\title{
Characteristics of Indicators for Insulation Deterioration in 26 kV Generator Stator Windings
}

\author{
Soo-hoh Lee*, Hee-dong Kim, Tae-sik Kong \\ Power Generation Laboratory, Korea Electric Power Corporation (KEPCO) Research Institute, Dae-jeon, South Korea \\ Email address: \\ leesoohoh@kepco.co.kr (Soo-hoh L.), hdkim90@kepco.co.kr (Hee-dong K.), tskong@kepco.co.kr (Tae-sik K.) \\ ${ }^{*}$ Corresponding author
}

To cite this article:

Soo-hoh Lee, Hee-dong Kim, Tae-sik Kong. Characteristics of Indicators for Insulation Deterioration in 26 kV Generator Stator Windings. American Journal of Electrical Power and Energy Systems. Vol. 8, No. 6, 2019, pp. 145-151. doi: 10.11648/j.epes.20190806.11

Received: September 23, 2019; Accepted: October 16, 2019; Published: November 4, 2019

\begin{abstract}
This study conducted and analyzed the results of non-destructive tests (AC current, dissipation factor, and partial discharge tests) and a destructive test (overvoltage test) on $26 \mathrm{kV}$-generator stator windings with a ground fault. The target generator was a steam turbine generator in operation for over 30 years, and ground fault in windings occurred because of the rapid and instantaneous temperature rise in the copper conductor owing to the partial loss of generator cooling water. By comparing the non-destructive test data measured during the planned preventive maintenance period two years before the ground fault and the data gathered just after the ground fault, the study conducted an in-depth analysis of the effect of moisture on insulation diagnosis factors. If both the dissipation factor and capacitance data increased when compared to those of previously estimated values at same applied AC voltage level, it represented that the insulation materials absorbed moisture. Moreover, it was further developed that both of the dissipation factor and capacitance surge voltage were detected when the discharge started whereas the concerned surge voltage for AC current was detected when the discharge was proceeded in some extent. It is expected that a wider understanding of insulation diagnosis factors developed from this study will contribute not only to a more reliable diagnosis data analysis but also a stable power supply by preventing accidents in advance.
\end{abstract}

Keywords: Insulation, Stator Winding, Generator, AC Current, Dissipation Factor, Capacitance, Partial Discharge, Overvoltage

\section{Introduction}

Generator stator windings that are operational over a long time suffer from progressive deterioration and ultimately undergo insulation failure owing to continuous discharge between phase and phase caused by dirt on the surface of endwinding and that in voids inside insulation materials caused from the windings' thermal, electric, mechanical, and environmental effects $[1,2]$. Sudden insulation failure of generator stator windings in operation reduces the reliability of power supply and makes rapid repair difficult, causing considerable economic loss. Accordingly, besides the US and Canada, South Korea has conducted research on insulation integrity assessment through off-line and on-line insulation diagnosis tests in generator stator windings [3-5].

In South Korea, regular insulation diagnosis tests are conducted to evaluate the insulation deterioration of off-line generator stator windings during the planned preventive maintenance for the early prevention of unexpected accidents. An insulation diagnosis test includes insulation resistance, polarization index, AC current, dissipation factor, and partial discharge, and the measured data are comprehensively analyzed to determine the level of insulation deterioration.

This study targets a steam turbine generator (800 MVA, 26 $\mathrm{kV}$ ) that is operational for over 30 years to perform the offline insulation diagnosis test and evaluate dielectric strength status of stator windings, and toward this end, a overvoltage test was conducted and its results were analyzed while permitting the voltage up to 1.25 times of the normal voltage at $26 \mathrm{kV}$, i.e., up to $32.5 \mathrm{kV}$.

The concerned generator suffered the dramatic temperature rise in the stator windings, which resulted in ground fault, when the cooling water for the generator stator windings was not partially supplied for approximately $10 \mathrm{~min}$ owing to the bus power loss while in operation. This study focuses on the insulation quality assessment by insulation diagnostic test 
two years before and right after the ground fault for the stator windings without the windings where the ground fault occurred. Furthermore, overvoltage test was performed to ensure insulation strength for the operation for the time being. While part of the defect types and discharge pattern analysis have been examined in the reference [6], it mainly focused on the conductor delamination discharge attributed to the rise of the windings temperature and its pattern analysis. In another previous study, insulation diagnosis was performed to evaluate the insulation quality of a $500 \mathrm{MW}, 22 \mathrm{kV}$ generator stator bars and a $350 \mathrm{MW}, 24 \mathrm{kV}$ generator stator windings. However, it was restricted to evaluate the condition of stator winding insulation by measuring $\mathrm{AC}$ current $(\Delta \mathrm{I})$, dissipation factor $(\Delta \tan \delta)$, partial discharge (PD) magnitude, and capacitance (C) [7]; in this study, to go further from the previous research, an in-depth analysis was performed on the significance of insulation diagnosis factor and correlation among those factors such as insulation resistance, polarized index, $\mathrm{AC}$ current, dissipation factor and capacitance, discharge inception voltage, and partial discharge data.

\section{Test Specimen Creation and Test Method}

This study discusses the off-line insulation diagnosis and insulation breakdown test on a $26 \mathrm{kV}$ gas turbine generator stator windings that are operational for over 30 years. In the case of the off-line insulation diagnosis test, $5 \mathrm{kV} \mathrm{DC}$ current was applied to the generator stator windings by phase to measure the polarized index (Automatic Insulation Tester, AVO International) before applying high AC voltage. For the AC current, dissipation factor and partial discharge tests on the generator stator windings, schering bridge, coupling capacitor, and partial discharge measuring detector (PDD, Tettex Instruments TE 571) were used. The schering bridge comprises a power supply (HV supply, Type 5283), bridge (Type 2818), and resonating inductor (Type 5285). AC current was applied to the generator stator windings by connecting the schering bridge (Tettex Instruments) to it, and the coupling capacitor (Tettex Instruments, 4,000pF) filtered the signal from the windings to the coupling unit (Tettex Instruments AKV 572), and the partial discharge detector measured the magnitude and pattern of the discharge. The frequency bandwidth of the partial discharge detector is between 40 and $400 \mathrm{kHz}$.

After the completion of the off-line insulation diagnosis test, a overvoltage test was conducted to determine whether the windings acquired the minimum insulation dielectric strength required for the operation of the generator. In the case of the overvoltage test, the HV supply $(50 \mathrm{kV})$ and the bridge (Type 2819) were used to increase the voltage by 1 $\mathrm{kV}$ and permit $32.5 \mathrm{kV}, 125 \%$ of the line-to-line voltage, for $1 \mathrm{~min}$.

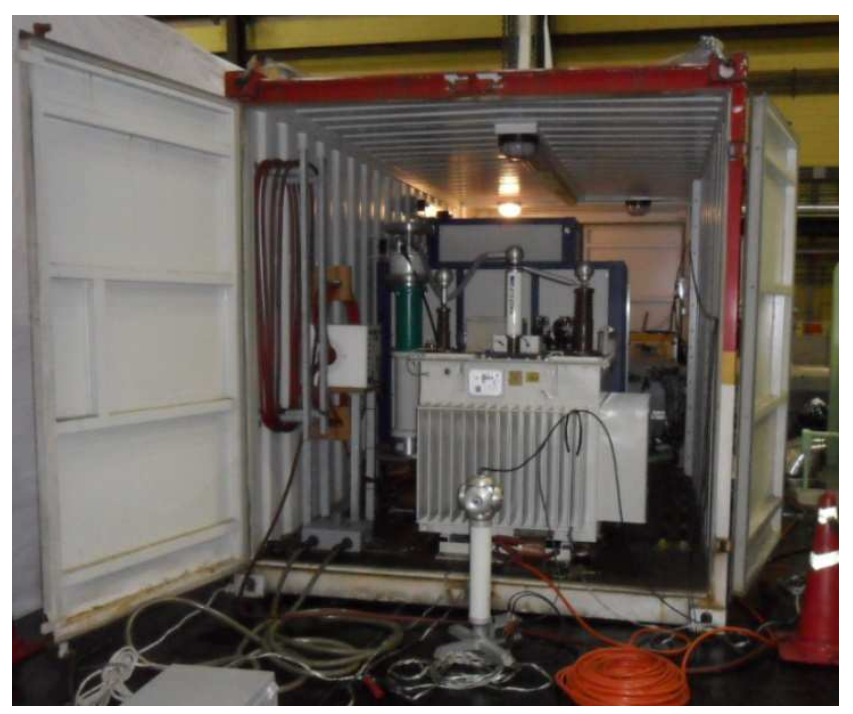

Figure 1. Construction of the insulation diagnosis and overvoltage test equipment.

\section{Test Results and Discussion}

\subsection{Check of IR and PI}

Table 1 shows the nominal ratings of a gas turbine generator that is operational for over 30 years.

Table 1. Nominal ratings of gas turbine generator.

\begin{tabular}{|c|c|c|c|c|c|}
\hline Generator & Nominal capacity [MVA] & Nominal voltage [kV] & Nominal current $[\mathrm{A}]$ & Insulation grade & Manufactured year \\
\hline $\mathrm{S} / \mathrm{T}$ & 800 & 26 & 17,765 & $\mathrm{~B}$ & 1983 \\
\hline
\end{tabular}

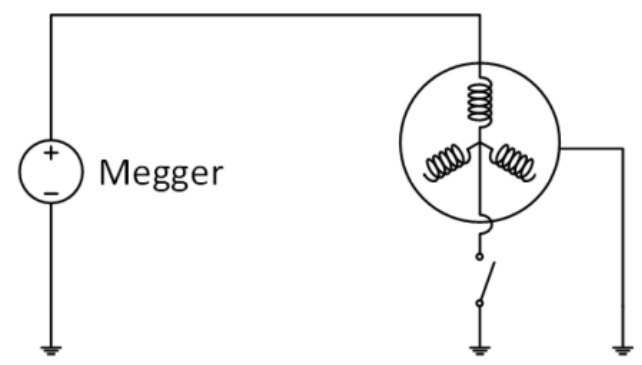

Figure 2. Circuit diagram for IR and PI test.
To verify whether the insulation intensity of the stator windings has already been deteriorated because of the absorption of moisture and pollution before performing the AC high-voltage test, the neutral point of the steam turbine generator was separated and the insulation resistance and polarized index at nominal AC voltage were examined by phase as shown in the circuit diagram in Figure 2.

Table 2 shows the insulation resistance and the polarized index test results by phase. In the case of phase B of the generator stator windings to ground fault, the concerned windings (No. $\Delta$, Upper windings, phase B) were 
disconnected, and the rest of the windings were connected, and the insulation resistance and polarized index were measured. As a result, the insurance resistance in all three phases exceeded the standard value of insulation resistance at $100 \mathrm{M} \Omega$, and the polarized index also exceeded the standard value at 2.0 [8]. Therefore, the analysis shows that the windings have insulation strength suitable for the AC highvoltage test.

Table 2. IR and PI test results.

\begin{tabular}{|c|c|c|c|}
\hline \multirow{2}{*}{ Types of bars } & \multicolumn{2}{|c|}{ IR [M $\Omega]$} & \multirow{2}{*}{ PI } \\
\hline & $1 \mathrm{~min}$ & $10 \mathrm{~min}$ & \\
\hline A & 1,390 & 4,860 & 3.50 \\
\hline B & 1,230 & 3,610 & 2.93 \\
\hline $\mathrm{C}$ & 2,800 & 5,590 & 2.00 \\
\hline
\end{tabular}

Two years before the ground fault, an off-line diagnosis was performed on the concerned generator as part of the preventive maintenance during the overhaul period. As a reference, the insulation resistance at phases $\mathrm{A}, \mathrm{B}$, and $\mathrm{C}$ at the time was 505, 460, and $492 \mathrm{M} \Omega$, respectively. The current insulation resistance and polarized index increased from the values two years ago, which signifies that the ratio of the leakage current to discharge current was higher two years ago as compared to the current test. In other words, it is believed that the reason for the higher insulation resistance and polarized index from this test is because of the large increase in the temperature of insulation materials during the fault, which helped remove the moisture in the insulation material.

\subsection{AC Current Estimation}

The AC current test determines the overall (average) insulation integrity of stator groundwall insulation. Shown in Figure 3 is the circuit diagram for performing the AC current test.

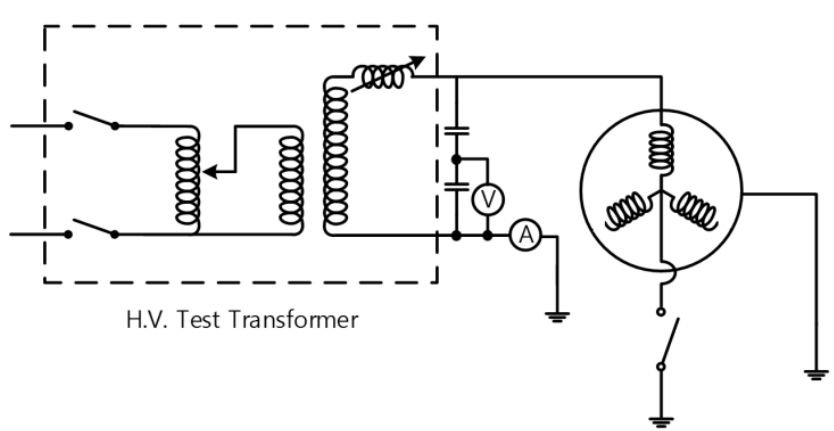

Figure 3. Circuit diagram for AC current estimation.

In this test, the neutral point of the steam turbine generator was separated, and AC voltage by phase was increased by 1 $\mathrm{kV}$ up to 1.25 times of nominal voltage at $26 \mathrm{kV}$, i.e., up to $32.5 \mathrm{kV}$, to measure the AC current. The test resulted in the AC current-voltage characteristics shown in Figure 4. Based on this, $\Delta \mathrm{I}$, a factor that shows the overall insulation integrity of the stator windings, was determined. $\Delta \mathrm{I}$ can be derived from the following equations.

$$
\begin{gathered}
\Delta \mathrm{Io}_{(15)}=\left(\mathrm{I}_{(15)}-\mathrm{Io}_{(15)}\right) / \mathrm{Io}_{(15)} \times 100[\%] \\
\Delta \mathrm{Io}_{(18.8)}=\left(\mathrm{I}_{(18.8)}-\mathrm{Io}_{(18.8)}\right) / \mathrm{Io}_{(18.8)} \times 100[\%]
\end{gathered}
$$

where $\mathrm{I}_{(15)}$ and $\mathrm{I}_{(18.8)}$ denote the estimated AC current at 15 $\mathrm{kV}$ (phase voltage) and $18.8 \mathrm{kV}$ (phase voltage $\times 1.25$ ), respectively. $\mathrm{Io}_{(15)}$ and $\mathrm{Io}_{(18.8)}$ denote the AC current at $15 \mathrm{kV}$ (phase voltage) and $18.8 \mathrm{kV}$ (phase voltage $\times 1.25$ ), assuming it is proportional to the value at $2 \mathrm{kV}$, respectively.

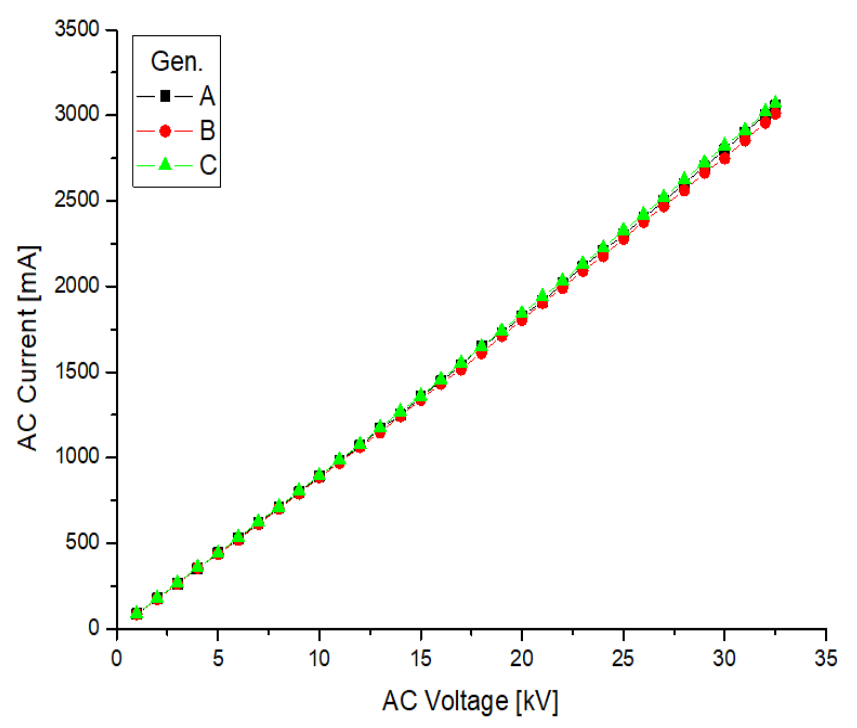

Figure 4. Characteristics of AC current vs. AC voltage in generator stator windings (Just after the occurrence of ground fault).

Table 3. Characteristics of AC current in generator stator windings (Just after the occurrence of ground fault).

\begin{tabular}{llll}
\hline \multirow{2}{*}{$\begin{array}{l}\text { Voltage } \\
{[\mathbf{k V}]}\end{array}$} & $\mathbf{A C}$ current $[\mathbf{m A} \mathbf{l}$ \\
\cline { 2 - 4 } & $\mathbf{A}$ & $\mathbf{B}$ & $\mathbf{C}$ \\
\hline 2.0 & 176.4 & 174.5 & 178.4 \\
15.0 & 1,357 & 1,336 & 1,359 \\
18.8 & 1,706 & 1,685 & 1,722 \\
$\mathrm{Io}_{(15)}$ & $1,323.0$ & $1,308.75$ & $1,338.0$ \\
$\mathrm{Io}_{(18.8)}$ & $1,658.16$ & $1,640.3$ & $1,676.96$ \\
$\Delta \mathrm{Io}_{(15)}[\%]$ & 2.56 & 2.08 & 1.56 \\
$\Delta \mathrm{Io}_{(18.8)}[\%]$ & 2.88 & 2.72 & 2.68 \\
$\mathrm{P}_{\mathrm{i} 1}[\mathrm{kV}]$ & 8.6 & 8.7 & 8.9 \\
\hline
\end{tabular}

Table 4. Characteristics of AC current in generator stator windings (Two years before the ground fault accident).

\begin{tabular}{llll}
\hline Voltage & \multicolumn{4}{l}{ AC current $[\mathbf{m A}]$} \\
\cline { 2 - 4 }$[\mathbf{k V}]$ & $\mathbf{A}$ & $\mathbf{B}$ & $\mathbf{C}$ \\
\hline 2.0 & 188.5 & 190.5 & 190.5 \\
15.0 & 1,419 & 1,435 & 1,437 \\
$\mathrm{Io}_{(15)}$ & $1,413.75$ & $1,428.75$ & $1,428.75$ \\
$\Delta \mathrm{Io}_{(15)}[\%]$ & 0.37 & 0.43 & 0.57 \\
\hline
\end{tabular}

The following can be determined from the test results in Table 3 and Table 4.

In Table 3, the AC current at certain voltage in phase B, the windings where the ground fault occurred, was lowest because - while this can be determined from the capacitance value measured by each phase later-as opposed to the other phases, the AC current in the phase B test circuit was measured without the coil where the accident occurred. 
$\Delta \mathrm{Io}_{(18.8)}$ in phases $\mathrm{A}, \mathrm{B}$, and $\mathrm{C}$ was $2.88 \%, 2.72 \%$, and $2.68 \%$, respectively. $\Delta \mathrm{Io}_{(15)}$ in phases $\mathrm{A}, \mathrm{B}$, and $\mathrm{C}$ in Table 4 , two years before the ground fault accident, was $0.37 \%$, $0.43 \%$, and $0.57 \%$, respectively, where $\Delta \mathrm{I}$ at the time was derived by applying the voltage up to $15 \mathrm{kV}$ due to the limitation of the test device capacity. Thus, to determine the $\Delta \mathrm{I}$ change trend just after the ground fault compared to the value two years ago under the identical voltage condition, the study newly acquired $\Delta \mathrm{Io}_{(15)}$ after calculating Io at $15 \mathrm{kV}$. This value at phases $\mathrm{A}, \mathrm{B}$, and $\mathrm{C}$ was $2.56 \%, 2.08 \%$, and $1.56 \%$, respectively. Compared to the values two years ago, the values after the ground fault accident increased by $2.19 \%$ p, $1.65 \%$ p and $0.99 \%$ p, respectively. As such, overall, there was considerable deterioration of the groundwall insulation within two years.

Meanwhile, the voltage at the point where the current surges is called current surge voltage, expressed as $\mathrm{P}_{\mathrm{i} 1}$. As shown in Figure 4, the current surge voltage appearing at phases $\mathrm{A}, \mathrm{B}$, and $\mathrm{C}$ was $8.6,8.7$, and $8.9 \mathrm{kV}$, respectively. The AC current surge point was caused by the discharge within micro voids, which will be discussed later, and there appears slightly higher voltage than the partial discharge inception voltage or tan $\delta$ surge voltage, and this shows that AC current surges not in the initial inception of the discharge but at the point when discharge occurs in the overall windings.

\subsection{Dissipation Factor (DF) Estimation}

The dissipation factor test is performed to determine the overall (average) insulation integrity of the stator groundwall insulation as well. Shown in Figure 5 is the circuit diagram for the dissipation factor test.

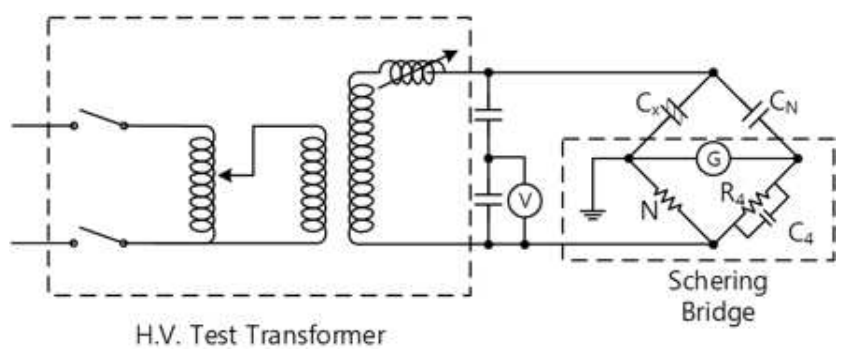

Figure 5. Circuit diagram for DF estimation.

This test also examined the change in the dissipation factor ( $\tan \delta)$ and capacitance while separating the neutral point of the steam turbine generator and increasing the voltage by 1 $\mathrm{kV}$ up to 1.25 times of the nominal voltage at $26 \mathrm{kV}$, i.e., up to $32.5 \mathrm{kV}$. Here $\Delta \tan \delta_{(15)}, \Delta \tan \delta_{(18.8)}$ are the values at $15 \mathrm{kV}$, the nominal phase voltage, and $18.8 \mathrm{kV}, 1.25$ times of the nominal phase voltage, respectively, minus the initial voltage $2 \mathrm{kV}$, which are the factors that show the overall (average) insulation deterioration of the groundwall insulation of the stator windings. The same method was used to derive $\Delta \mathrm{C}_{(15)}$ and $\Delta \mathrm{C}_{(18.8) \text {. }}$

As shown in Figures 6 and 7, the $\tan \delta$-voltage and $\mathrm{C}$ voltage characteristics graphs, the dissipation factor and capacitance values tend to increase with the voltage.
Furthermore, the AC current at certain voltage clearly shows the lowest phase B because, as has been mentioned, the AC current was measured without the capacitance that corresponds to the coil part where the fault occurred. The comparison of the dissipation factor-voltage characteristics in Figure 6 and the capacitance-voltage characteristics in Figure 7 shows that they share similar patterns despite different physical properties.

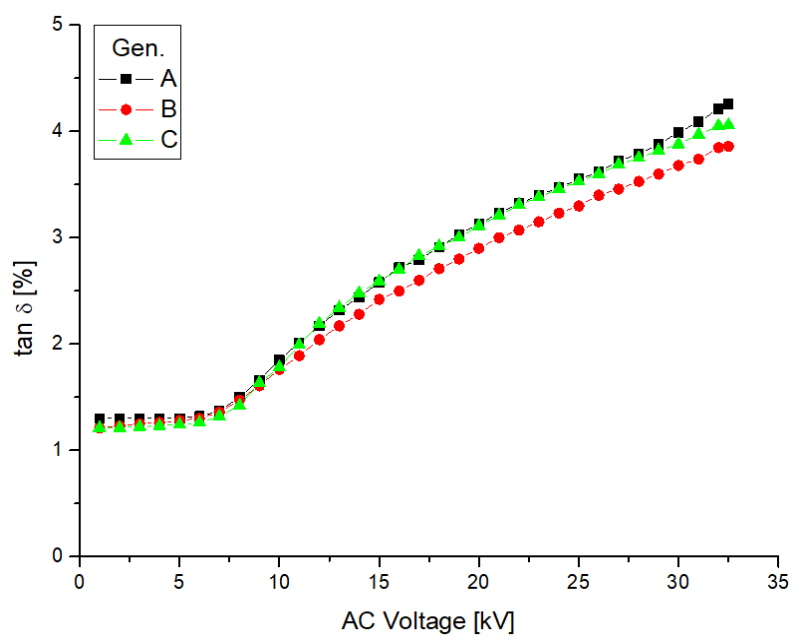

Figure 6. Characteristics of DF in generator stator windings (Just after the occurrence of ground fault).

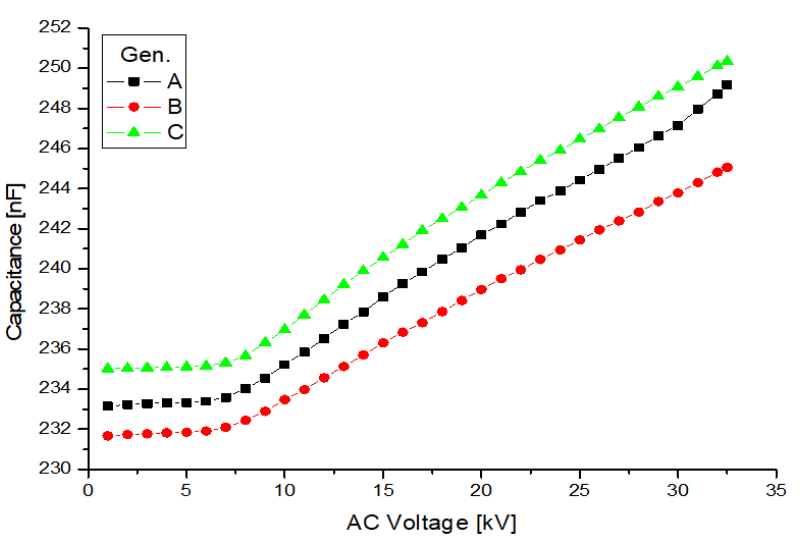

Figure 7. Characteristics of Capacitance in generator stator windings (Just after the occurrence of ground fault).

Table 5. Characteristics of DF \& $C$ in generator stator windings (Just after the occurrence of ground fault).

\begin{tabular}{lllll}
\hline & Voltage $[\mathbf{k V}]$ & $\mathbf{A}$ & $\mathbf{B}$ & $\mathbf{C}$ \\
\hline & 2.0 & 1.34 & 1.34 & 1.35 \\
& 15.0 & 2.59 & 2.43 & 2.60 \\
$\mathrm{DF}$ & 18.8 & 3.02 & 2.79 & 3.05 \\
{$[\%]$} & $\Delta \tan \delta_{(15)}$ & 1.25 & 1.09 & 1.25 \\
& $\Delta \tan \delta_{(18.8)}$ & 1.68 & 1.45 & 1.70 \\
& Surge point & 7.0 & 7.0 & 7.0 \\
& 2.0 & 233.23 & 231.69 & 235.00 \\
& 15.0 & 238.69 & 236.18 & 240.44 \\
$\mathrm{C}$ & 18.8 & 240.98 & 238.16 & 242.98 \\
{$[\mathrm{nF}]$} & $\Delta \mathrm{C}_{(15)}$ & 5.46 & 4.49 & 5.44 \\
& $\Delta \mathrm{C}_{(18.8)}$ & 7.75 & 6.47 & 7.98 \\
& Surge point & 7.0 & 7.0 & 7.0 \\
\hline
\end{tabular}


Table 6. Characteristics of $D F \& C$ in generator stator windings (Two years before the ground fault accident).

\begin{tabular}{lllll}
\hline & Voltage $[\mathbf{k V}]$ & $\mathbf{A}$ & $\mathbf{B}$ & $\mathbf{C}$ \\
\hline $\mathrm{DF}$ & 2.0 & 1.82 & 1.85 & 1.83 \\
{$[\%]$} & 15.0 & 2.87 & 2.82 & 2.90 \\
& $\Delta \tan \delta_{(15)}$ & 1.05 & 0.97 & 1.07 \\
$\mathrm{C}$ & 2.0 & 245.8 & 248.0 & 248.2 \\
{$[\mathrm{nF}]$} & 15.0 & 250.5 & 252.3 & 253.2 \\
& $\Delta \mathrm{C}_{(15)}$ & 4.7 & 4.3 & 5.0 \\
\hline
\end{tabular}

As shown in Table 5, $\Delta \tan \delta_{(18.8)}$ at phases $\mathrm{A}, \mathrm{B}$, and $\mathrm{C}$ after the ground fault was $1.68 \%, 1.45 \%$, and $1.70 \%$, and $\Delta \mathrm{C}_{(18.8)}$ was $7.75,6.47$, and $7.98 \mathrm{nF}$, respectively. As a reference, as shown in Table $6, \Delta \tan \delta_{(15)}$ at phases $\mathrm{A}, \mathrm{B}$, and $\mathrm{C}$ two years before the fault was $1.05 \%, 0.97 \%$, and $1.07 \%$ and $\Delta \mathrm{C}$ was $4.7,4.3$, and $5.0 \mathrm{nF}$, respectively. As in Table $5, \Delta \tan \delta_{(15)}$ and $\Delta \mathrm{C}_{(15)}$ were derived to determine the trend in the change from the measured values after the current ground fault under the identical voltage condition. The comparison results showed that $\Delta \tan \delta$ by each phase to two years was $0.20 \% \mathrm{p}, 0.12 \%$, and $0.18 \% \mathrm{p}$, and $\Delta \mathrm{C}$ was $0.76,0.19$, and $0.44 \mathrm{nF}$, respectively. As such, it is shown that $\Delta \tan \delta$ and $\Delta \mathrm{C}$ are the factors verifying that the overall deterioration in the groundwall insulation has considerably progressed as in the change of the AC current within two years.

Meanwhile, as opposed to the measurement of AC current, the advantages of measuring both the dissipation factor and capacitance at the same time are as follows. First, it can be determined from Table 5 and Table 6 that at a certain voltage ( 2 and $15 \mathrm{kV}$ ), $\mathrm{C}$ value and $\tan \delta$ decreased from those two years before the fault. Considering that the insulation materials have been dried up because of the increase in the windings temperature right after the ground fault, the decrease in $\mathrm{C}$ and $\tan \delta$ values imply that the insulation materials have become dry. Conversely, if both factors increase, the insulation materials have absorbed more moisture than the previous diagnosis. Particularly, in the case of the absorption of moisture, the initial dissipation factor would have a large starting value. Thus, the comparison of the changing trend of the dissipation factor and capacitance values to the values from the previous diagnosis will be useful in determining the moisture absorption of insulation materials.

Next, the voltage at which there is a surge of the dissipation factor and capacitance was identical in all phases at $7 \mathrm{kV}$. The surge voltage value of the dissipation factor and capacitance tend to appear somewhat earlier than the surge voltage of the AC current, and as it will be discussed later, it appears at a similar point in time to the discharge inception voltage. Thus, the dissipation factor and capacitance surge voltage is a factor for indirectly determining when the partial discharge starts.

\subsection{Offline PD Test}

Even if there is a huge defect in insulation materials, the dissipation factor value may become satisfactory if the number of defects is small and the rest of the insulation materials are in good condition. Through the partial discharge test, the magnitude and pattern of the maximum void inside the insulation materials can be easily determined [9-11]. Therefore, the information about the maximum void that cannot be determined by the AC current and dissipation factor can be verified by the partial discharge test for online as well as offline [12-14]. Shown in Figure 8 is the test circuit diagram for offline PD estimation.

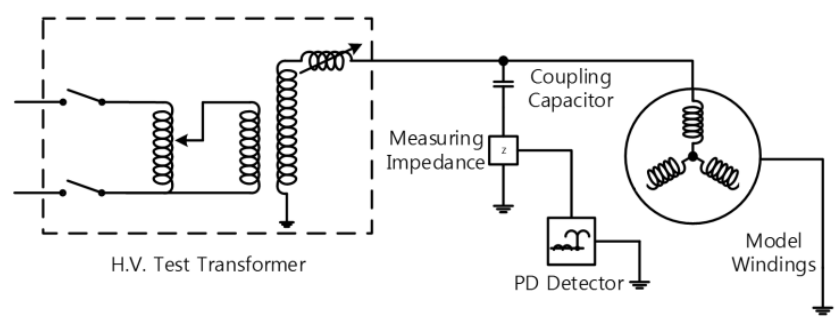

Figure 8. Circuit diagram for offline PD estimation.

Table 7 shows the results of measuring the magnitude of partial discharge by separating the generator stator windings by phase and applying $\mathrm{AC}$ voltage by phases $\mathrm{A}, \mathrm{B}, \mathrm{C}$. The inception voltage of the partial discharge measured at the site was approximately $7 \mathrm{kV}$. Here, the voltage at which the dissipation factor and capacitance surge were similar to the inception voltage for the partial discharge.

The partial discharge magnitude at $15 \mathrm{kV}$, the phase voltage of the generator, measured by phases $\mathrm{A}, \mathrm{B}$, and $\mathrm{C}$ was $33,300,20,900$, and $24,000 \mathrm{pC}$, respectively. The partial discharge magnitude by phases $\mathrm{A}, \mathrm{B}$, and $\mathrm{C}$ measured two years ago was $7,100,6,900$, and $7,300 \mathrm{pC}$, respectively, showing that the size significantly increased.

Also, the partial discharge pattern mainly shows the conductor delamination discharge as shown in Figure 9. Considering that the partial discharge pattern two years ago was an internal discharge pattern, it is believed that as dramatic rise in Joule's heat attributed to the loss of cooling water (the surface temperature at the insulation material of the stator windings was $153^{\circ} \mathrm{C}$ ), heat expansion occurred in the copper conductor, and the insulation material showed delamination as its heat expansion was lower than the copper conductor.

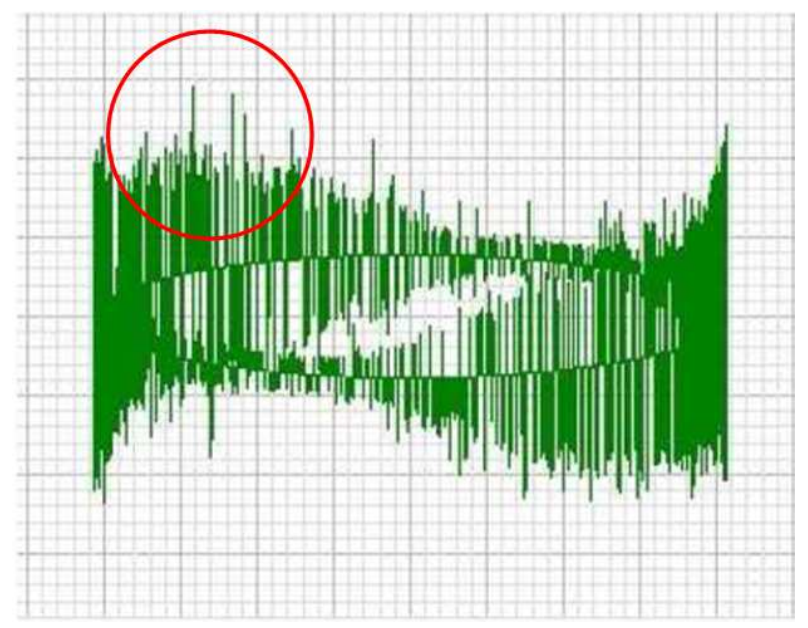

Figure 9. PD estimation $(20,900 \mathrm{pC} 15.0 \mathrm{kV})$. 
Table 7. Offline PD test results.

\begin{tabular}{lll}
\hline Phase & $\begin{array}{l}\text { Discharge inception } \\
\text { voltage (DIV) }[\mathbf{k V}]\end{array}$ & $\begin{array}{l}\text { Magnitude of PD at } 15.0 \mathbf{~ k V} \\
\text { [pC] }\end{array}$ \\
\hline A & 7.25 & 33,300 \\
B & 7.1 & 20,900 \\
C & 6.5 & 24,000 \\
\hline
\end{tabular}

Compared to the test results two years ago, the nondestructive tests (AC current, dissipation factor, and partial discharge tests) showed that in the case of the insulation deterioration in the generator stator windings, the rising point of the dissipating factor, the current surge point of AC current, and the inception voltage of the partial discharge all move to a lower voltage, and that the insulation failure also occurs at a low voltage.

Generally, the insulation strength of a $26 \mathrm{kV}$ generator is deemed to be satisfactory and its operation is possible if it is at or over $2 \mathrm{E}+1 \mathrm{kV}$, i.e., $53 \mathrm{kV}$. However, the target steam turbine generator is in decrepit state after having been in operation for over 30 years and because of the possibility of additional insulation failure during the test, the overvoltage test, which aimed to verify the insulation strength, was conducted by maintaining the voltage at 1.25 times of the nominal voltage at $26 \mathrm{kV}$, i.e., $32.5 \mathrm{kV}$, for $1 \min$ [15]. This is about 2.17 times higher than the phase voltage normally applied between the stator windings and ground. Because there was no insulation failure from the overvoltage test result, it is believed that if the corresponding windings from the ground fault and surrounding windings are replaced, the stator windings are shown to have the minimum insulation strength for the operation in the meantime. Compared to the condition two years ago, however, the insulation deterioration has progressed, and considering the deterioration history and the future operation plan, it is advised that the whole stator windings be re-wound as soon as possible.

\section{Conclusion}

This study conducted an off-line insulation diagnosis to evaluate the insulation deterioration of the stator windings of a steam turbine generator that is operational for over 30 years (800 MVA, $26 \mathrm{kV}$ ) while removing the affected windings after the ground fault. By comparing the data from the diagnosis test conducted two years ago on the identical generator, the study performed an in-depth analysis of the relationship among insulation factors, and ultimately, determined the possibility of a short-term operation of the generator by conducting a overvoltage test up to 1.25 times of the nominal voltage at $26 \mathrm{kV}$, i.e., $32.5 \mathrm{kV}$. The study concluded the following results.

(1) The study conducted a DC insulation diagnosis test, which measured the insulation resistance and polarized index, in the generator phases $\mathrm{A}, \mathrm{B}$, and $\mathrm{C}$, while having removed the windings where the ground fault occurred. This test was to determine the insulation strength of insulation materials before applying AC high voltage, and particularly, to identify the absorption of moisture.

(2) It was verified that both AC current and dissipation factor deviation values were the factors that showed the average insulation deterioration state of the whole stator windings. However, as for the AC current, the concerned surge voltage was detected when there was overall insulation deterioration in the windings whereas the dissipation factor and capacitance surge voltage were detected when the discharge started. Particularly, if both the dissipation factor and capacitance data increased when compared to the previous values, it meant that the insulation materials absorbed moisture.

(3) Even if there are partially huge voids, if their number is small, they are not significantly reflected onto the change of the AC current and dissipation factor, and therefore, the partial discharge test was conducted to analyze the largest discharge magnitude and its pattern. The partial discharge test results showed that maximum size of the void in the target generator stator winding insulations increased compared to the data measured two years before the ground fault, and its pattern was that of the conductor delamination discharge. It is believed that this was because of the delamination between the copper body and insulation as it dramatically expanded by Joule's heat with the loss of cooling water in the concerned generator.

It is hoped that having analyzed the diagnosis data of the generator, which had ground fault after being operational for over 30 years, the study conducted an in-depth analysis of the effect of surrounding environments (absorption of moisture) on insulation diagnostic factors and the interaction among the diagnosis factors so as not only to improve the reliability of the diagnosis but also to contribute to a more stable supply of electricity.

\section{References}

[1] H. D. Kim, "Analysis of Insulation Aging Mechanism in Generator Stator Windings," J. Korean Inst. Electr. Electron. Mater. Eng., vol. 15, No. 2, pp. 119-126, 2002.

[2] R. Morin, R. Bartnikas, and P. Menard, "A Three-Phase MultiStress Accelerated Electrical Aging Test Facility for Stator Bars," IEEE Trans. on Electrical Conversion, vol. 15, No. 2, pp. 149-156, 2000.

[3] H. D. Kim, T. S. Kong, S. K. Lee, B. S. Kim, and D. Y. Kim, "Analysis of Off-Line and On-Line Partial Discharge in High Voltage Motor Stator Windings," J. Electr. Eng. Technol., vol. 10, No. 3, pp. 1086-31092, 2015.

[4] H. D. Kim, "Analysis of Insulation Quality in Large Generator Stator Windings," J. Electr. Eng. Technol., vol. 6, No. 2, pp. 384-390, 2011.

[5] H. Zhu, V. Green, and D. Huynh, "Application of On-Line versus Off-Line PD Testing for Stator Insulation Monitoring," Electrical Insulation Conference and Electrical Manufacturing \& Coil Winding Conference, pp. 175-178, 1999. 
[6] T. S. Kong, H. D. Kim, T. S. Park, K. Y. Kim, and H. Y. Kim, "Analysis of Partial Discharge Patterns for Generator Stator Windings," American J. Electrical Power Energy Sys., vol. 4, No. 2, pp. 17-22, 2015.

[7] H. D. Kim, T. S. Kong, Y. H. Ju, and B. H. Kim, "Analysis of Insulation Quality in Large Generator Stator Windings," Journal of Electrical Engineering \& Technology, vol. 6, No. 2, pp. 384-390, 2011.

[8] IEEE Standard, "IEEE Recommended Practice for Testing Insulation Resistance of Electric Machinery," IEEE Std. 43, 2013.

[9] Hazlee Illias, Teo Soon Yuan, Ab Halim Abu Bakar, Hazlie Mokhlis, George Chen, and Paul L. Lewin, "Partial Discharge Patterns in High Voltage Insulation," IEEE International Conference on Power and Energy (PECon), pp. 750-755, 2012

[10] Wei Wang, Lin Yan, Tianzheng Wang, Hua Yu, Yu han, Xingting Liu, Na Zhang, and $\mathrm{Na} \mathrm{Wu}$, "PD Mechanism and Pattern Investigation for Stator Winding Insulation of HV Motors," in Proceedings of 2016 IEEE International Conference on Mechatronics and Automation, Harbin, August 2016.
[11] Claude Hudon and Mario Bélec, "Partial Discharge Signal Interpretation for Generator Diagnostics," IEEE Trans. on Dielectrics and Electrical Insulation, vol. 12, No. 2, pp. 297319, 2005.

[12] H. D. Kim, T. S. Kong, T. S. Park, and T. H. Son, "Analysis of On-Line Partial Discharge Trend in Gas Turbine Generators", International Journal of Energy and Power, vol. 3, no. 3, pp. 42-48, 2014.

[13] H. D. Kim, T. S. Kong, S. K. Lee, B. S. Kim \& D. Y. Kim "Analysis of off-line and on-line partial discharge in high voltage motor stator windings", Journal of Electrical Engineering \& Technology, Vol. 10, No. 3, pp. 1086-1092, 2015.

[14] G. C. Stone, C. Chan, and H. G. Sedding, "On-line Partial Discharge Measurement in Hydrogen-Cooled Generators," in 2016 IEEE Electrical Insulation Conference, Montréal, Canada, June 2016.

[15] IEEE Standard, "IEEE Guide for Insulation Maintenance of Electric Machines,” IEEE Std. 56, 2016. 